\title{
An Examination on Biomass Power as Primary Energy and Generation of Electricity using Biomass
}

\author{
Merin Antony, Shanthi, D.Kirubakaran
}

\begin{abstract}
With genuine concern all inclusive and in India on the utilization of petroleum products, it is vital for India to begin utilizing sustainable power sources. India is the seventh biggest nation on the planet traversing 328 million hectares and abundantly presented with sustainable wellsprings of vitality. Among the sustainable power sources, biomass assumes an indispensable part particularly in country regions, as it constitutes the real vitality source to lion's share of family units in India. Biomass vitality is the usage of natural issue introduce and can be used for different applications.

As indicated by the Intergovernmental Panel on Climate Change, biomass represented $10.2 \%$ of the world's aggregate yield of primary energy. The International Energy Agency extends that it will be the quickest developing sustainable power source amongst now and 2030, giving as much as 30\% of the power devoured worldwide by 2050. In India, woodland and agricultural biomass is the most as often as possible utilized organic matter because of its prepared accessibility and the development of the producing technique included. India delivers around 450-500 million tons of biomass for each year. Biomass gives $32 \%$ of all the essential vitality use in the nation at display.
\end{abstract}

\section{INTRODUCTION}

Numerous created and creating nations has advanced biomass vitality age through instrumented arrangements and money related motivations. Numerous administrations presented sustain in tax conspires as an arrangement system to quicken interest in sustainable power source division. India is a quick creating nation; with high monetary and mechanical development vitality request is likewise developing. The significant source satisfy the vitality necessity of India are Oil and coal. The vitality utilization of India utilizing these customary sources are $-151.3 \mathrm{GW}$ by warm (coal, gaseous petrol and oil), $4.78 \mathrm{GW}$ by atomic vitality, $30.49 \mathrm{GW}$ by hydro and $27.54 \mathrm{GW}$ by sustainable power source1.

Biomass vitality utilization is practically speaking in India since antiquated time. It is utilized as a part of the type of dairy animals compost cake, kindling, husk and numerous accessible characteristic sustain stocks. In any case, coordinate utilization of biomass in strong shape was not protected and effortless as they create part of smoke and slag. Consequently Biogas plant are being propelled by Indian

Revised Manuscript Received on November 22, 2019.

Merin Antony, Research Scholar, Sarvapalli Radhakrsihnan University, Bhopal.

Dr. Shanthi, Assistant Professor, Sarvapalli Radhakrsihnan University, Bhopal.

Dr. D.Kirubakaran, Professor \& HOD /EEE dept. St. Joseph's Institute of Technology, OMR, Chennai
Govt. as they deliver no smoke i.e. contamination free2. Numerous appropriations are given to foundation of the biogas plant. New biomass gasification Technology was likewise advanced which changes over biomass in to syngas, which are more proficient. This paper/research work deals with the investigation on biomass power generation concepts, analysis and statistics of electric power generation.

\section{OUTPUT AND COSTS}

In a cogeneration (power and steam) plant filled by woods biomass, $30 \%$ to $35 \%$ of the energy in the strong biomass can be changed over into power, amid the steam cycle3. By recovering the warmth created and utilizing it for different purposes, add up to effectiveness can surpass $80 \%$.

From 1999 to 2012, forthright expenses for woodland biomass in India were much lower and steadier than for fuel oil. Notwithstanding the specialized framework required for biomass control costs marginally more than practically identical advancements using petroleum derivatives. The reason: since biomass has a lower density than non-renewable energy sources, a bigger amount of crude material and therefore broader framework are expected to produce a similar measure of power.

Tackling urban and agricultural products biomass would be profitable, especially regarding kept away from landfill costs, which have climbed essentially lately.

\section{ADVANTAGES AND DISADVANTAGES}

- Relatively low and stable forthright expenses for woodland biomass

- Continuous wellspring of energy, not at all like breeze and photovoltaic sun oriented power

- Energy densityis lower than petroleum products

- Large-scale activities costly in light of the fact that biomass resources are broadly scattered

- Need to manufacture biomass-energized cogeneration plants close to the asset or close power transmission lines

- Complexity of utilizing urban biomass, especially in view of waste decent variety and the need for arranging tasks, an assortment of preparing innovations, and so on5.

\section{SUSTAINABLE DEVELOPMENT}

The principle issues related with creating power from forest biomass are the following: 
- Reclamation of modern wood squander, which would otherwise be sent to landfill.

- Loss of biodiversity and soil consumption if deficient cut is left nearby.

- Production of air contaminants amid biomass combustion and transportation.

- Biomass stockpiling sway: contaminant draining, scent and stylish disturbances.

- Production of end squander that can be difficult to recover because of its metal substance6.

\section{DIFFERENT TYPES OF BIOMASS}

In India, there are three sorts of biomass with huge energy potential: forest biomass, agricultural products and urban biomass. Of these, forest or woodland biomass exists in the best amounts, with slice as yet offering critical potential for advancement7.

- Forest or Woodland biomass - kindling, wood handling waste (bark, sawdust and shavings, trim closures, edgings, mash and-paper plant water treatment ooze) and slice (branches, needles, leaves, trunks and tree tops) To energize the advancement of timberland biomass as a wellspring of energy, a consistent supply of crude materials must be secured. As of now, that supply relies upon the amount of timber collected by organizations with timber supply and woodland administration contracts.

- Agricultural product biomass - products, plant and creature farming waste, and waste produced by the agricultural products preparing industry Crop and animals search yields rely upon a few components, including climate, soil quality, trim writes and the measure of water and compost gave. Since conditions in northern nations are by and large less good for agriculture than in the tropics, profitability is lower. Developing yields and domesticated animals for sustenance and developing foodstuffs to deliver energy are in coordinate rivalry. A more noteworthy interest for biomass would directly affect supply costs and the accessibility of the crude materials required to create this asset.

- Urban and solid biomass - civil water-treatment plant slop and putrescible natural waste from the private, commercial and institutional areas Efforts are under approach to make urbanbiomass processing advancements more proficient. To build the social acceptability of cogeneration plants in urban settings, information and discussion gatherings must be held with the groups being referred to.

\section{DIFFERENT TECHNIQUES TO HARNESS BIOMASS ENERGY}

The techniques used to deliver energy with biomass shift contingent upon the kind of biomass and its proposed utilize. In India, the burning of strong biomass is a typical practice; biomechanization and gasification are additionally intriguing roads to investigate.

- Solid biomass Combustion: Combustion is a thermo chemical procedure that produces coordinate warmth.
Woody biomass is comprised of ranger service or agricultural products squander: bark, branches, straw, sawdust, wood pellets, and so on. Utilized as fuel for boilers, hot air heaters or wood stoves, this essential energy source gives high temp water, hot air or steam. The steam would then be able to be utilized to create power, among different purposes.

In India, a few organizations and healing facilities utilize biomass to create power that they use for their own particular purposes or pitch to different shoppers.

- Bio-mechanization - It is a procedure for stabilizing natural issue through aging, without the nearness of oxygen. The biogas created is made out of methane and carbon dioxide and may contain hints of different gases relying upon the substrate utilized. It can be delivered in a bioreactor, with a maintenance time of 1 to 50 days. It can likewise be separated from landfills, where it is delivered normally more than 10 to 40 years. This ignitable gas is utilized to produce warm and additionally power.

In India, a few organizations create biogas to meet their own particular energy needs. Civil water treatment plants and a few landfills with the correct offices additionally create power.

- Gasification:It is a procedure that produces ignitable gas by responding strong or fluid fuel with a gasification operator, for example, air or oxygen, at climatic pressures. The biomass is totally or incompletely changed into an ignitable gas, primarily under the impact of warmth. This gas is made basically out of hydrogen and carbon monoxide, alongside minute amounts of methane, carbon dioxide and tar. Gasification happens in a gasifier as a dry process, or in a digester as a wet procedure. The flammable gas can be utilized to control an evaporator to deliver steam or a turbine or generator to create power. It can likewise be utilized as a part of cogeneration and as a crude material in a concoction transforming procedure to create fluid biofuels.

\section{ENVIRONMENTAL CHANGE AND AIR QUALITY}

Regardless of which producing technique is utilized, air discharges are one of the principle ecological effects of biomass control. Leaving aside the energy required to gather, transport and process the crude materials, creating energy from biomass spares about as much ozone harming substance as consuming petroleum derivatives produces. The $\mathrm{CO} 2$ at last created does not add to the nursery impact since it originates from the $\mathrm{CO} 2$ contained in the environment. Then again, the $\mathrm{CO} 2$ created by consuming petroleum products and discharged into the air contributes to the nursery impact since it originates from the carbon contained in the world's hull. 
Air emanations are liable to various controls governing the utilization of biomass. For wood warming, for example, the city of Montréal disallows the establishment of non-affirmed fire places or woodstoves that consume something besides wood pellets, petroleum gas or propane.

\section{- Life cycle evaluation}

At the point when its whole life cycle is viewed as, the ecological footprint of biomass control is by and large marginally more noteworthy than that of other sustainable power source choices, however impressively not as much as that of non-renewable energy source based warm alternatives. At last, that smaller affect is because of the unrivaled productivity of the joined warmth/power yield and to the recovery of modern wood squander, which would somehow go into landfills.

- Biological systems and biodiversity

Gathering biomass in logging zones must be controlled to keep up woodland biodiversity and profitability and save soil and water quality. Slash assumes a vital part in woodland biological systems. Like fertilizer, it improves soil and controls its causticity. Expelling slice to deliver energy could significantly affect the recharging of touchy backwoods cover like jack pine developing on coarse sand.

\section{- Wellbeing and personal satisfaction}

Consuming woods biomass might be unsafe to human wellbeing because it can result in smog, which is made out of fine particles suspended in the environment. Consuming urban biomass can release metals and different poisons into the air, which can likewise be unsafe to human wellbeing and the earth. Nearby or provincial biomass advancement can decrease the requirement for transporting crude materials, relieving the effect on wellbeing and nature.

- Local economy

Biomass advancement can prompt critical funds by eliminating the need to pulverize or cover extensive amounts of waste. Biomass controls secures the supply of warm and electrical energy and fortifyenergy security. The additional power sold to clients or nearby merchants is another wellspring of revenue, guaranteeing the organization's long haul survival.

With the crude material scattered crosswise over India, nearby economic spinoffs are noteworthy. Building biomass-handling plants and biomass-filled cogeneration plants can empower local improvement, while building an undeniable biomass control industry can give new force to work creation and training and help keep gifted laborers in the districts.

- Social adequacy

The social adequacy of biomass improvement ventures is dictated by different variables. They incorporate the accompanying: The advantages of decreasing waste for the group, alongside the related ecological effect; appropriate activity of biomass preparing plants and biomass-powered cogeneration plants.

\section{CONCLUSION}

From investigation of this examination we can presume that immense potential exist for investigation of accessible biomass in India to change over it to vitality. Different assets in wide assortment and distinctive type of biomass are accessible in India. Different sources are there to acquire squander biomass e.g. agrarian waste, nourishment squanders, mechanical wastewaters created in huge volumes which indicates the inclination to change over to non regular wellspring of vitality. Organizations and enterprises are rehearsing the transformation of various waste biomass to vitality in India and announced advantages from these. At show two noteworthy advancements are being utilized to change over biomass into vitality; thermo-substance and bio-synthetic. Choice of transformation innovations for biomass relies on the shape in which the vitality is required like ignition create warm, mechanical, power vitality; pyrolysis, maturation and mechanical extraction deliver fluid powers reasonable for use as transportation energizes and so on. Gasification prepared biomass to frame syngas. Different tasks identified with biomass control age are introduced in different province of India for satisfy vitality prerequisite by biomass gasification. The states are additionally creating power by baggase cogeneration which utilizes the misuse of sugar factories. Various power age ventures are as of now demonstrated fruitful in India in view of gasification based cogeneration rustic jolt plants. These plants have not just tackled the rustic jolt issue for the remote towns, where infrastructural expenses could have been very high for ordinary zap, yet additionally the power age cost has likewise been moderately low.

\section{REFERENCES}

1. EurObserv'ER. 2010. "Baromètrebiogaz - Biogaz Barometer". Le journal des énergiesrenouvelables, vol. 200. pp. 104-119.

2. Guangpeng M, Ying Z (2013) Current situation and problems of biomass enerᄀgy development in China. Management of Agricultural Science and Technology.

3. Intergovernmental Panel on Climate Change. Renewable Energy Sources and Climate Change Mitigation. (Online.) 2011. srren.ipcc-wg3.de/report/IPCC_SRREN_Full_Report.pdf. Document accessed on November 10, 2014.

4. McIlveen-Wright, D.R., et al., A Techno-economic assessment of the reduction of carbon dioxide emissions through the use of biomass cocombustion. Fuel, 2011. 90(1): p. 11-18.

5. Observ'ER. Worldwide Electricity Production from Renewable Energy Sources. (Online.) 2013. www.energies-renouvelables.org/observ-er/ html/inventaire/Eng/methode.asp. Site accessed on November 10, 2014.

6. Ohimain, E.I. (2012) The Prospects and Challenges of Waste Wood Biomass Conversion to Bioelectricity in Nigeria.Journal of Waste Conversion, Bio-Products and Biotechnology, 1, 3-8.

7. Okello C, Pindozzi S, Faugno S, Boccia L (2013) Development of bioenergy technologies in Uganda: A review of progress. Renew Sustain Energy Review 18: 55-63.

8. Oluoti, K.O., Doddapaneni,T.R.K., Kanagasabapathi, D. and Richards, T. (2014) Evaluation of the Pyrolysis and Gasification Kinetics of Tropical Wood Biomass. BioResources, 9, 2179-2190.http://dx.doi.org/10.15376/biores.9.2.2179-2190

9. Oyedepo, S.O. (2012) Energy and Sustainable Development in Nigeria: The Way Forward. Energy, Sustainability and Society, 2, 15 http://www.energsustainsoc.com/content/2/1/15

10. Popoola, L.T., Gutti, B., Adeniran, J.A. and Adeoye, B.K. (2013) The Potentials of Waste-to-Energy System in Nigeria: A Study of Pyrolysis Conversion of Wood Residue to Bio-Oil in Major Cities of South-Western Nigeria. Advances inApplied Science Research, 4, 243-251. 
11. Roche Ingénieurs-conseils. (Online.) 2008. Étude de préfaisabilité Chaufferiesinstitutionnelles à la biomasseforestière. Report presented to the Quebec Wood Export Bureau. 102 p. www.agrireseau. qc.ca/energie/documents/QWEB- Chaufferies_centrales-Rapport_ final_04-07-20081.pdf. Document accessed on November 10, 2014.

12. Scarlat N, Dallemand JF, Banja M (2013) Possible impact of 2020 bioenergy targets on European Union land use. A scenario-based assessment from naᄀtional renewable energy action plans proposals. Renew Sustain Energy Re $\neg$ view 18: 595-606.

13. The Gaia Project. Electricity Generation: Biomass. (Online.) 2014 www.thegaiaproject.ca/wp-content/uploads/2012/08/biomass.pdf. Document accessed on November 10, 2014.

14. Yingli L, Jian W, Xiaotian C (2013) Biomass briquette fuel and its power genera $\neg$ tion technology. Journal of Agricultural Mechanization Research 6: $226-229$. 